methyl salicylate ointment, etc. Our correspondent wonders if an injection of horse serum would be of benefit in increasing the coagulability of the blood.

INCOME TAX.

Schedule E : Expenses.

"C. R. G." has claimed to deduct from his salary expenses incurred for medical periodicals and upkeep of medical library. The inspector of taxes has refused the claim, referring him to the decision of Rowlatt, J., in the case of Simpsou $v$. Tate.

* * The refusal is in accordance with the law, as judicially laid dowu; "C. R. G." has no prospect of appealing successfully unless he can show that the purchase of the medical literature (or membership of the societies distributing it to him) was a condition of his appointment to the office he holds.

\section{Cash Basis.}

"R. M. W." is being pressed by the iuspector of taxes to render his firm's returus on the basis of actual bookings; past returns have been prepared by chartered accountants on the basis of actual receipts.

* * It is officially agreed, we believe, that the basis of actual bookings is incorrect and also unfair to the practitioner unless it is modifled by the deduction-authorized by law-of a carefully made estimate of anticipated loss by reason of bad debts. That estimate it is almost impossible to prepare in such circumstances as " R. M. W.'s," except ou the basis that the percentage lost in the past is likely to be the ratio of loss in the futare. If the amount of debts outstanding does not differ materially from one year to another, the result of taking such an estimate will be the same as of preparing the returns on a cash basis. This is the reason why it is a well recognized custom on the part of inspectors of taxes to accept the cash basis in the case of medical practices. If our correspondent's gross bookings have been increasing, then the " cash" returns are lagging behind the true earnings of the practice, and he has no answer (theoretically, at least) to the inspector's contention, but if bookings are not increasing, we think that an application to the Board of Inlaud Revenue, Somerset House, would probably receive sympathetic consideration.

" P., T., and R."-A, B, and C were in partnership nntil June 30th, 1926, when $A$ left the firm, uudertaking not to act as a general practitioner, but carried on as a surgeon and consultant. How should the assessment for 1926-27 be dealt with, and can A and/or $B$ and C claim "specific cause"?

* * The old ratio of division will, of course, apply for the first quarter of 1926-27. For the remaining three quarters the average should be reconstructed, separating $A$ 's specialized work from the general practice now carried on by $B$ and $C$ and dividing the remainder of the assessment accordingly. The question of "specific cause" is, in the circumstances, somewhat intricate, and, as it is at present a hypothetical one, we suggest that it be referred again when the result of the next acconuts-that is, for nine months to March 31st, 1927-is available.

\section{Estate Duty.}

"M.D."-Dr. X. died in 1918, leaving a small estate. His will provided inter alia for payment of an annuity of $\$ 80$ to a claim payment of a further estate duty upon the sum which had been invested to provide for paymeut of the aunuity.

*** The facts appear to be within the rule laid down in Attorney-General $v$. Watson and others [1917], 2 K.B., 427, in which it was held that the cesser of an annuity gives rise to a claim for duty. In dealing with the statutory provisions (Finauce Act, 1894, Sec. 2 (1) (b), Lush, J., said: “The object of the section is to make estate duty payable whenever there has been a succession, in fact, or that which is equivalent to a succession-whenever there bas been a cesser of an anunity by reason of the death of the annuitant, which cesser causes a benefit to accrue to that property."

\section{LETTERS, NOTES, ETC.}

\section{Cholecystography.}

Mr. G. P. B. HUdDY, M.S., F.R.C.S. (Dudley Road Hospital, Birmingham), writes: The fatality following the injection of sodium tetraiodophenolphthalein, referred to in your issue of September 18th (p.542) and again on October 2nd (p.620), occurred in a patient unler my care and was brought to the notice of the medical profession in the Lancet of September 4th (p. 509).

The patient was a woman, aged 46 , and her weight was 11 st. $11 \mathrm{lb}$. The dose given was $5 \frac{1}{2}$ grams in $40 \mathrm{c.cm}$. Of triple distilled water, this being the maximum dose used by Professor D. P. D. Wilkie (BRITISH MEdICAI. JournaL, 1925, ii, p. 1046): I gave the injection myself, and it was carried out very slowly, during a period of over twenty minutes. During the injection the patient complained of abdominal pain, which was followed by vomiting and headache. Immediately after the completion of the injection the pain became so severe that she rolled about and screamed. The body became rigid, there was frothing at the month, and then loss of consciousness. The pulse and respiration became more and more feeble, the pupils dilated and death ensued in spite of all efforts at resuscitation.

The makers of the preparation were immediately informed and samples were tested, but no alteration in the compound could be detected. I should like to point out that, contrary to my previous practice, the solution had been made up the day before use. Another patient injected immediately preceding and under similar circumstances had a more severe reaction than is usual.

The amount of drug used by different workers has varied, and, in view of the above experience, I feel that some patients are particularly susceptible, and that the amount given in this case is too high for general use. This would seem to be confirmed by Mr. Stanford Cade, who, using a smaller maximum dose of $4 \frac{1}{2}$ grams, observed in two consecutive cases a very similar train of symptoms to that described above. In describing the cases he states ". . . the pulse at the wrist could not be felt for half to three-quarters of an hour" (Lancet, Jnly 3rd, p. 5). The injection of the solution in two portions, with a short interva between, is a safeguard, for the symptoms develop rapidly, and by adopting th

The value of intravenous injection of sodium tetraiodophenolphthaleiu is to be estimated by the increased percentage of correct diagnoses so obtained over that obtained by ordinary clinical and other means of investigation, including oral administration of the drug.

\section{An Acid Dentrifrice.}

DR. W. J. Henson (London, W.) writes: Six years ago (JournaL, 1921 , vol. $i$, p. 408) you published a letter from me under the above heading. I have had before me correspondence from doctors and dentists in all parts of the world, aud up to the present not one has controverted my assertion that chalk and soap, forming the basis of the major part of the tooth pastes in modern use, depress the flow of alkaline saliva, which is Nature's preventive of pyorrhoea and dental decay. Un the occasion to preventive of pyorrhoea and dental decay. On the occasion to which I refer I gave the ingredients of a fruit acid tooth paste
formula which I had used in my practice for $\mathbf{3}$ number of years, and now, after this lapse of time, I am in a position to confirm my former statement that $I$ have never seen a recurrence of pyorrhoea or decay in any case in which it has been properly used.

Plumbo-solvent Waters.

"Hydraulic Engineer" writes: The method advocater by Dr. T. D. Harries (Uctober 23rd, p. 764) for safeguarding the publio against dangers incurred by the use of lead pipes for the conveyance of soft water is as effective as it is simple, and can be applied with equal advantage to the water supplies of towns, villages, schools, and country houses. It is now for the authorities to broadcast the information given by Dr. Harries, which can justly be proclaimed as a most valuable contribution in the cause of public health.

\section{Garlic in Pneumonia.}

Dr. C. J. HILI AITKEN (Kilnhurst, Yorks), writing with reference to a Memorandum by Dr. F. W. Crossman (JoU RNAI, 1924, vol. i p. 519), in which it was stated that the use in pneumonia of a spirituous tincture of the garlic bulb brought about a rapid cure a spirituous tincture of the garlic bulb brought about a rapid cure,
relates that in two cases under his care in which it was proposed to employ this remedy the crisis oocurred on the fifth and sixth days of the illness respectively, and before the drug was obtained. In another case the crisis came after a dose of castor oil, and in yet another after a change in the medicine. Subseguently to reading the article on garlic, he noticed a statement made at a medical meeting that pueumonia had changed its type and was tending to abort much sooner than the eighth day. In twelve tending to abort much sooner than the eighth of months he had a series of thirty-six cases of pnemmonia in which the treatment was on ordinary lines, without one death. He of pneumonia in the usual way, and that the good results ascribed to garlic may be of the nature of post hoc ergo propter hoc.

\section{Corrigenda.}

THE writer of the review of the current issue of Brain in last week's JoURNAL (p. 798) calls attention to a sentence in which the insertion of the word "and" changed its meaning. The sentence commences in the ninth line of the second paragraph of the review and should read as follows: "It is found that when the drum is rotated in a clockwise direction viewed from above, nystagmus develops in an individual watching the drum," etc.

IN the report of the discussion on "Surgery and the Workmen's Compensation Act" at the Royal Society of Medicine (JourNaL, October 30th, p. 788), by a reporter's slip the few remarks stated to have been made by Mr. Maynard Smith should have been attributed to Mr. Maynar due to both gentlemen.

\section{VACANCIES.}

Notifications of offices vacant in universities, medical colleges, and of vacant resident and other appointments at hospitals will be found at paves $47,48,49,52$, and 53 of our advertisement columns, and advertisements as to partnerships, assistantships, and locumtenencies at pages 50 and 51 .

A short summary of vacant posts notifled in the advertisement columrs appears in the Supplement at page 207. 